\title{
Successful removal from the esophagus of a self-expandable metal stent that had shriveled up into a tangled ball
}
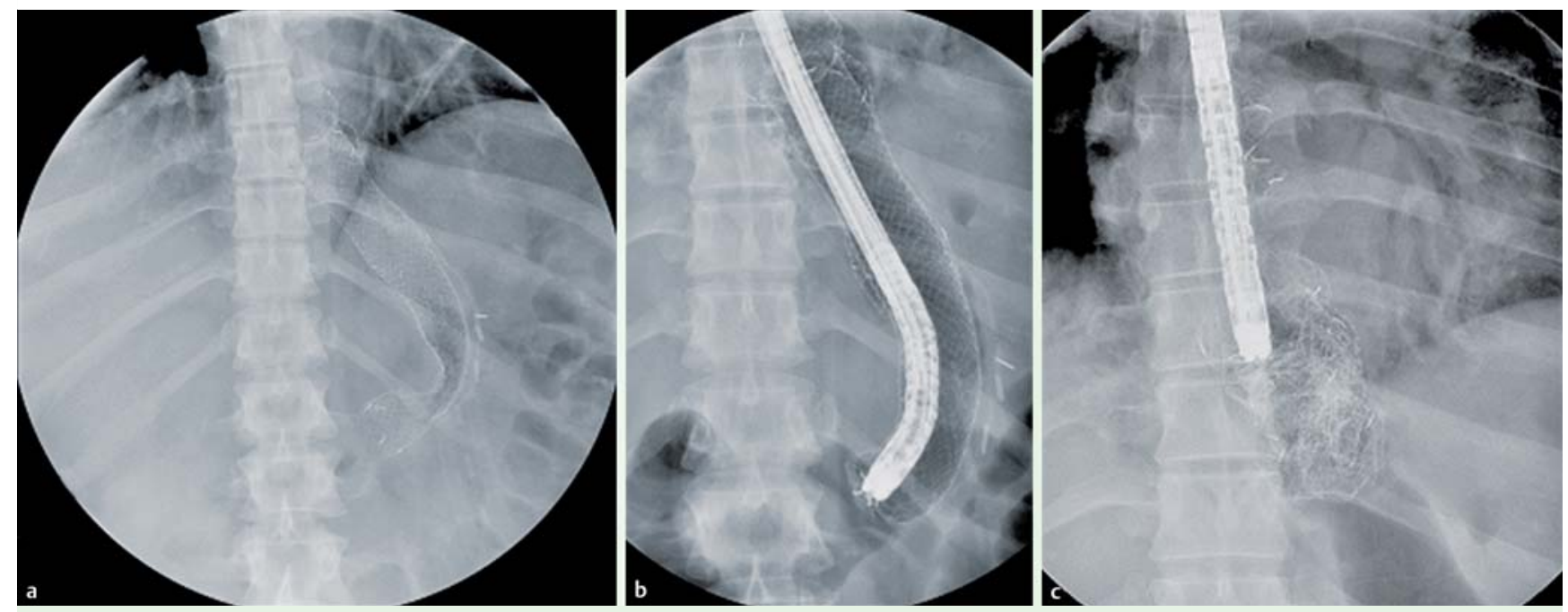

Fig. 1 Radiographic views showing: a the 18-cm covered self-expandable metal stent (SEMS) in position at the esophagogastric junction; b a foreign-body forceps being used to grasp the distal lasso stitch of the SEMS during its removal; $\mathbf{c}$ the SEMS shriveled up into a tangle of metal wire in the mid-esophagus.

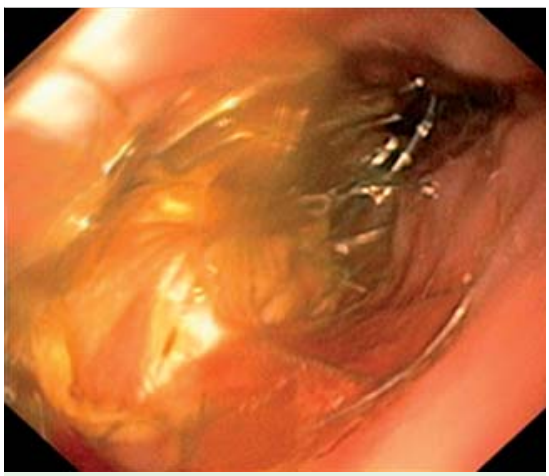

Fig. 2 Endoscopic view of the self-expandable metal stent (SEMS) contracted into a knot of metal wire.

A 39-year-old woman developed a leak from the cardia following a sleeve gastrectomy. She underwent placement of an 18-cm Niti-S covered esophageal self-expandable metal stent (SEMS; TaeWoong Medical, Gimpo, Korea) at the gastroesophageal junction ( $\bullet$ Fig. 1 a).

The patient returned to undergo stent removal 4 weeks after its placement. During this procedure the lasso stitch at the distal end was grasped with endoscopic foreignbody forceps and was pulled ( $\bullet$ Fig. $1 \mathbf{b}$ ). The stent began to invaginate from within but soon shrank into a tangled ball of metal wires ( $\bullet$ Fig. $1 \mathrm{c}$ and $\bullet$ Fig.2). The distal

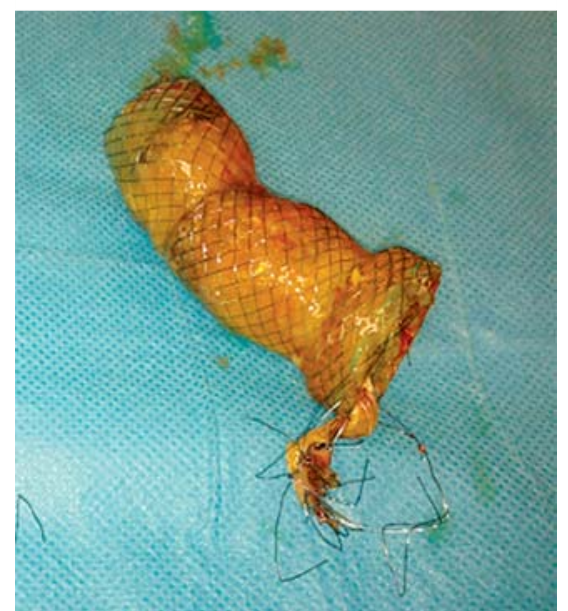

Fig.3 The broken self-expandable metal stent (SEMS) after its removal.

lasso stitch slipped out of the forceps, leaving the now compacted SEMS lying in the mid-esophagus and completely obstructing the lumen.

The SEMS was gradually eased away from the esophageal mucosa using the proximal lasso stitch. The disjointed mesh wires were slowly pulled off the mucosa, and thereby the whole of the stent was successfully removed under fluoroscopic guidance ( $\bullet$ Fig.3). Endoscopy confirmed the absence of any esophageal injury, but

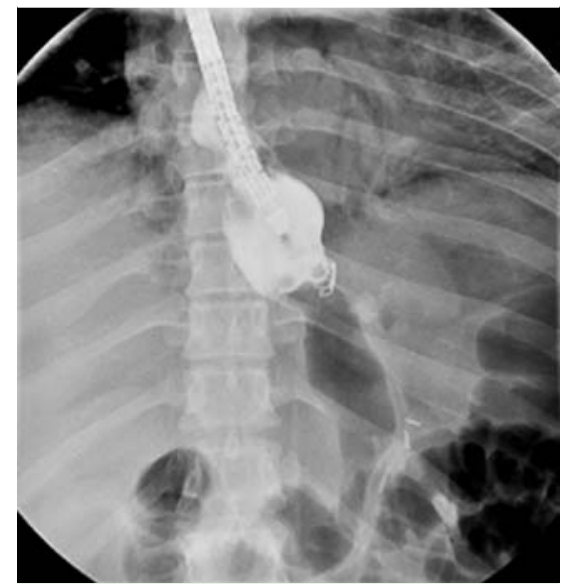

Fig.4 Radiographic view showing an overthe-scope clip (OTSC) in position to treat the leak from the cardia after the self-expandable metal stent (SEMS) had been removed.

persistence of the original leak was noted. An over-the-scope clip (OTSC) was used to obliterate the leak ( $\bullet$ Fig.4).

Fracture of an esophageal SEMS has been previously described, during positioning because of defective material and as a consequence of laser therapy that caused a late spontaneous fracture during palliative treatment [1]. It appears that corrosion is the principal cause of fracture because, once in place and fully expanded, SEMS are not subject to any great mechanical 
stress [2]. Cases of fracture during removal of a covered biliary SEMS have also been described [3].

Here we report the first case, to our knowledge, of a covered SEMS compacting into a ball at the time of removal and its successful retrieval. We believe that this happened probably because the SEMS was partially fractured and became deeply embedded in the esophageal mucosa; when traction was applied, the now-damaged mesh contracted in on itself because of the inherent forces in its structure. The risk of a SEMS curling up should be considered as a potential complication of SEMS removal, in addition to other well-documented complications [4].

Endoscopy_UCTN_Code_CPL_1AJ_2AF

Competing interests: None
Gianfranco Donatelli ${ }^{1}$, Parag

Dhumane $^{2}$, Bertrand M. Vergeau' ${ }^{1}$, Jean-Loup Dumont ${ }^{1}$, Thierry Tuszynski ${ }^{1}$, Bruno Meduri ${ }^{1}$

${ }^{1}$ Therapeutic Endoscopy Unit, Hôpital Privé des Peupliers, Paris, France

2 Department of General and Laparoscopic Surgery, Lilavati Hospital and Research Center, Mumbai, India

\section{References}

1 Reddy AV, Alwair H, Trewby PN. Fractured esophageal nitinol stent: Report of two fractures in the same patient. Gastrointest Endosc 2003; 57: 138-139

2 Rana SS, Bhasin DK, Sidhu GS et al. Esophageal nitinol stent dysfunction because of fracture and collapse. Endoscopy 2009; 41 (Suppl. 02): E1701-E1702

3 Joo KR, Paik CN, Chung WC et al. Fracture of self-expandable metal stent during endoscopic removal in benign biliary stricture. Clin Endosc 2013; 46: 95-97
4 Donatelli G, Dhumane P, Perretta $S$ et al. Endoscopic placement of fully covered self expanding metal stents for management of post-operative foregut leaks. J Minim Access Surg 2012; 8: 118-124

Bibliography

DOI http://dx.doi.org/

10.1055/s-0033-1344992

Endoscopy 2013; 45: E410-E411

(c) Georg Thieme Verlag KG

Stuttgart · New York

ISSN 0013-726X

Corresponding author

\section{Gianfranco Donatelli, MD}

Hôpital Privé des Peupliers - Unité d'Endoscopie Thérapeutique

8 Place de l'Abbé G. Hénocque

Paris 75013

France

Fax: +33-1-44165212

donatelligianfranco@gmail.com 